\title{
Long Term Incentives for Residential Customers Using Dynamic Tariff
}

\author{
Huang, Shaojun; Wu, Qiuwei; Nielsen, Arne Hejde; Zhao, Haoran; Liu, Zhaoxi
}

Published in:

Proceedings of APPEEC 2015

Link to article, DOI:

10.1109/APPEEC.2015.7380991

Publication date:

2015

Document Version

Peer reviewed version

Link back to DTU Orbit

Citation (APA):

Huang, S., Wu, Q., Nielsen, A. H., Zhao, H., \& Liu, Z. (2015). Long Term Incentives for Residential Customers Using Dynamic Tariff. In Proceedings of APPEEC 2015 IEEE. https://doi.org/10.1109/APPEEC.2015.7380991

\section{General rights}

Copyright and moral rights for the publications made accessible in the public portal are retained by the authors and/or other copyright owners and it is a condition of accessing publications that users recognise and abide by the legal requirements associated with these rights.

- Users may download and print one copy of any publication from the public portal for the purpose of private study or research.

- You may not further distribute the material or use it for any profit-making activity or commercial gain

- You may freely distribute the URL identifying the publication in the public portal 


\title{
Long Term Incentives for Residential Customers Using Dynamic Tariff
}

\author{
Shaojun Huang, Qiuwei Wu, Arne Hejde Nielsen, Haoran Zhao, Zhaoxi Liu \\ Centre for Electric Power and Energy, Department of Electrical Engineering \\ Technical University of Denmark \\ 2800 Kgs. Lyngby, Denmark \\ \{shuang, qw, ahn, hzhao, zhliu\}@elektro.dtu.dk
}

\begin{abstract}
This paper reviews several grid tariff schemes, including flat tariff, time-of-use, time-varying tariff, demand charge and dynamic tariff (DT), from the perspective of the long term incentives. The long term incentives can motivate the owners of flexible demands to change their energy consumption behavior in such a way that the power system operation issues, such as system balance and congestion, can be alleviated. From the comparison study, including analysis and case study, the DT scheme outperforms the other tariff schemes in terms of cost saving and network operation condition improving.
\end{abstract}

Index Terms-Tariff scheme, congestion management, system balance, renewable energy.

\section{INTRODUCTION}

Renewable energy has been growing continuously in the last few decades and have already become an important player in the electricity energy market of many countries and regions. For example, Denmark has a wind share of 39 percent of the total electricity consumption in 2014 [1] and has set its energy strategies that aim at being independent from fossil fuels by 2050 [2]. On one hand, wind power (and solar power) offers the society with very clean energies; on the other hand, it challenges the secure operation of the power system, e.g. system balance among others, due to the intermittence feature of wind power and many other renewable energy.

The system balance issue should be normally handled by the transmission system operator (TSO). From the historical market data of the west region of Denmark (DK-West) provided by the Danish TSO (Energinet.dk), including hourly wind production and hourly gross consumption of year 2014 (see Fig. 1, upper part), it can be seen that the wind production was sometimes more than the total consumption but sometimes was near zero production due to the fluctuation of the wind. Therefore, the TSO should export the redundant wind power to neighboring countries (in the case of Denmark) when the wind production was more than the gross consumption and should import or start up the large traditional power plants when there was not enough wind.

In the future, as the renewable energies keep growing and eventually cover 100 percent of the total consumption, the traditional power plants will be phased out one by one and it will become more and more difficult to achieve the system balance through importing and exporting the deficit/redundant energy from/to the neighboring countries. Many methods have been proposed to deal with this issue in recent years. Employing a large amount of flexible demands, such as electrical vehicles ( EVs) and heat pumps ( HPs), is one of the methods that can help achieve the system balance by improving the behavior of the demand side with energy storage systems, e.g. batteries of EV and hot water tanks and thermal inertia of HP.

The flexible demands themselves can, however, have significant impacts on the power systems with creating issues, such as congestions in the distribution networks due to simultaneous charging or discharging. It is therefore a big challenge for the distribution system operator ( DSO) to accommodate flexible demands as much as possible and offer incentives to the owners of these flexible demands if they provide help to the system balance or other system operation issues. New tariff (a charge on the residential customers by the DSO) schemes are needed to handle this challenge. This paper investigates the traditional tariff schemes and several newly introduced tariff schemes, including DT (dynamic tariff) scheme proposed in [3], [4], which not only takes into account the fluctuating energy prices (see Fig. 1, bottom part) reflecting the system balance issues (deficit/redundant of wind power) but also the congestion costs due to the potential network congestions. The focus is given to the analysis of the long term incentives offered by these tariff schemes to the residential customers who own the flexible demands. The paper then uses a numerical study to compare the long term incentives offered by the traditional tariff scheme and the DT scheme. The paper ends with conclusions and future work. 

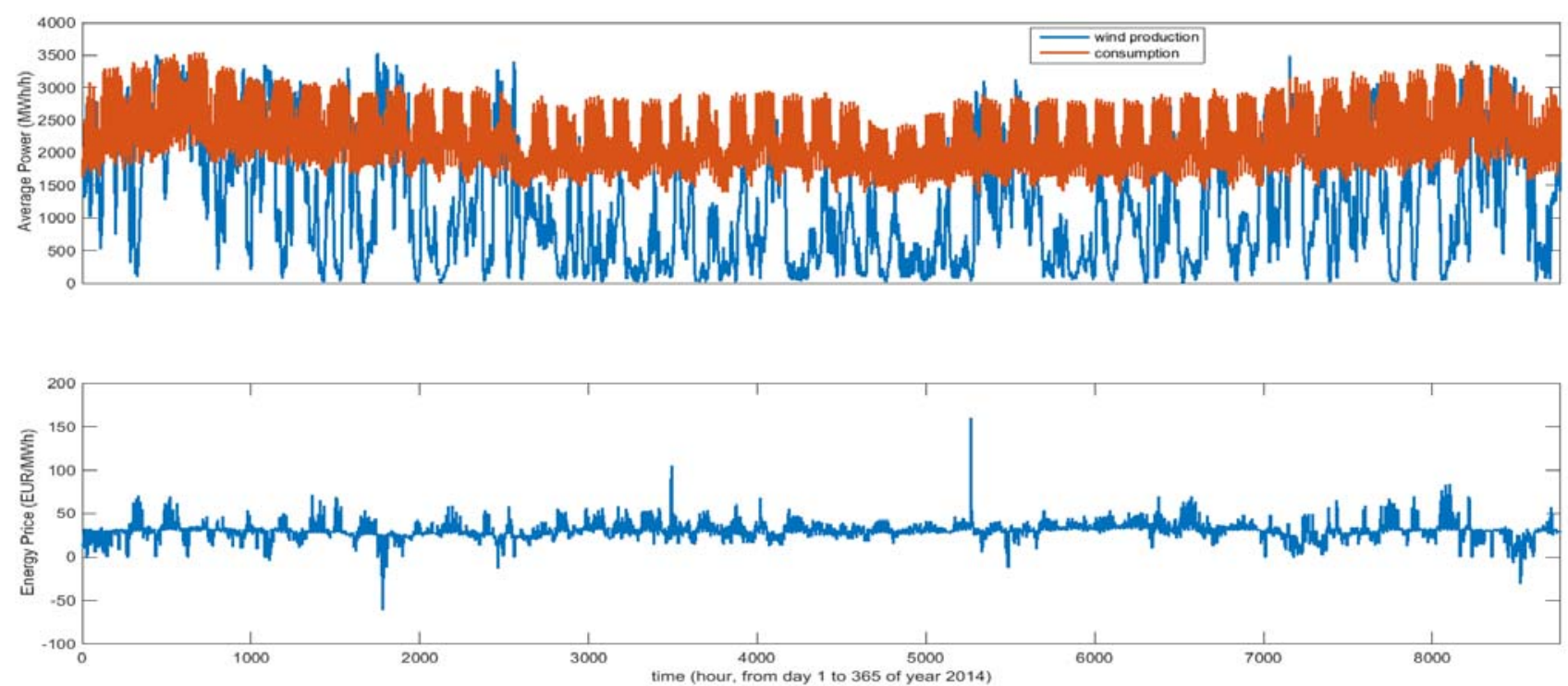

Fig. 1. Market data of DK-West, year 2014, data is downloaded from Energinet.dk (http://www.energinet.dk/EN/El/Engrosmarked/Udtraek-af-markedsdata/Sider/default.aspx)

\section{ANALYSIS OF DIFFERENT TARIFF SCHEMES}

\section{A. Flat Tariff}

Flat tariff is a traditional tariff scheme and has been employed by DSO in many countries for many years. In the flat tariff scheme, a fixed price is charged by the DSO on their customers, which can be roughly decomposed into two components, i.e. the energy cost and the other cost consisting of the distribution grid maintenance cost, investment and allowed profit. The final price paid by the customers includes also energy transport cost (paid to TSO) and taxes (paid to government) which are always flat for every customer all the time and therefore are not considered in this paper since they have no impact on the analysis of the long term incentives offered by different tariff schemes.

The flat tariff scheme offers no incentive to the customers to change their consumption behavior; the owners will consume electricity at their earliest convenience, e.g. charge EVs as soon as arriving home and turn on HPs whenever needed, which can make the system balance issue even worse. Therefore new tariff schemes are needed and they should be economically efficient such that the customers will choose the new tariff scheme voluntarily (the DSO should still offer the option of flat tariff scheme for those who are not comfortable with new tariff schemes).

In countries having deregulated electricity market, the DSO needs to buy electricity from spot market having varying energy price (see Fig. 1) and resale it to customers with fixed energy price (the energy cost part of the flat tariff). Therefore the flat tariff will be recalculated periodically, e.g. once a year in the case of Denmark, in order to balance the energy cost. To simplify the comparison among the different tariff schemes, it is assumed that the DSO has a very good forecast such that the flat tariff is determined in a way that the total energy cost paid by the customers is the same as the one paid by the DSO in spot market, i.e. no deficit or surplus.

\section{B. TOU Tariff}

The TOU (time of use) tariff scheme has two or more price levels in the tariff structure. During the peak time of the energy consumption (normally day time), the tariff has a higher energy price while during the off-peak time it has a lower energy price. Though the TOU tariff scheme can motivate the customers to shift their electricity consumption from peak time to off-peak time and therefore smooth the energy consumption level which is very beneficial to the system balance of the power system if it is consisting of many large power plants, especially the nuclear power plants, it has very limited benefit if the system is mainly consisting of fluctuating renewable energies, such as wind power. Another drawback of this tariff scheme is that a new peak can be created when the tariff switches from high to low. The severity of the new peak depends on how many flexible demands in the network.

\section{DC Tariff}

The demand charge (DC) tariff [5] scheme has been employed in some Nordic countries, such as Finland and Norway, where the DSO offers this tariff scheme in addition to the basic one, i.e. flat tariff scheme. In the DC tariff scheme, a rate that is put on the peak demand that is measured during the most cold/warm periods of one year is charged in addition to the energy rate which is related to the consumption of electricity, which is a bit lower than the energy rate of the flat tariff. In principle, if the customers do not change consumption behavior, the cost for them will be the same when choose one of these two schemes. Therefore, the customers have incentives to choose the DC tariff if they are willing to change their consumption behavior, e.g. reduce the 
peak demand. The benefits to the power system are similar to those by using TOU, e.g. smoothing the energy consumption level. But the same as TOU, one of the disadvantages is that it cannot benefit a system with high renewable energies.

\section{Time-varying Tariff}

The time-varying tariff has hourly energy provision rates which are based on the time-series of spot market prices and load curves with weighted factors [6]. The tariff is recalculated every day and therefore well accommodates the fluctuation of the energy prices reflecting the system balance. The customers are expected to change their consumption behavior according to the time-varying tariff and the system balance issue can be alleviated as a result. The authors of [6] did not consider the situation that all flexible demands consume the electricity simultaneously at the time slot with lowest energy rates since they are assumed to be greedily pursuing the minimum energy cost and not binding with any contracts that can limit their maximum power consumption. New peaks and congestions can occur and they can be very severe if the maximum power of the individual flexible demand is two or three times as high as the traditional household peak consumption, e.g. the charging power of EV with 3-phase chargers can be as high as three times of the traditional household peak.

\section{E. DT}

In the DT scheme, the tariff is time-varying and locational depending on the congestion cost of the load points [3], [4]. In order to be comparable with the above tariff schemes, the spot market prices are included in the tariff in addition to the locational congestion cost, leading to locational pricing. Another difference from the time-varying tariff scheme is the way how it is integrated into the existing energy market. The DT scheme employs the "aggregator" concept where the owners of flexible demands are represented by an aggregator and participate into the energy market through aggregators. The DSO publishes the DT before the energy market closes and therefore the aggregators can make their energy plans based on the DT signals and are restrained with the energy plans according to the energy market rules. Hence the DT scheme can benefit the power system in terms of alleviating the system balance issue without creating new peaks and congestions like other tariff schemes. The drawback of this tariff scheme is that its locational pricing mechanism discriminates the customers at different locations which is not allowed by present regulations in many countries. Method that can remove the discrimination is needed or new regulations allowing discrimination at the distribution level is needed in the future.

\section{CASE STUDY}

The numerical study was carried out using the Bus 4 distribution network [7] which is shown in Fig. 2. Focus is given to feeder one where L2, L4, L6, L8, L9, L11, and L12 refer to the transformers connecting the corresponding load points (LP1 to LP7, see Fig. 2). The detailed data of these load points are listed in Table I. EVs are the only flexible demands in this study and the conventional loads are not responsive to the price signals. Each household has one EV (commercial customers do not have EV) and the energy cost of one household consists of the cost for the conventional loads and the cost for the EV. The key parameters of the simulation model are listed in Table II. The EV availability shown in Fig. 3 is from the driving pattern study in [8].

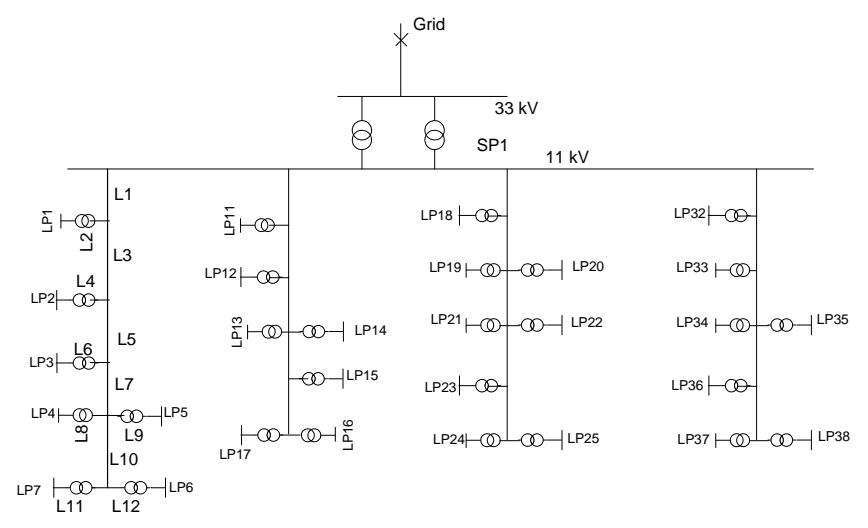

Fig. 2. Single line diagram of the distribution network

TABLE I

LOAD POINT DATA

\begin{tabular}{llll}
\hline $\begin{array}{c}\text { load } \\
\text { points }\end{array}$ & $\begin{array}{c}\text { customer } \\
\text { type }\end{array}$ & $\begin{array}{c}\text { peak conv. } \\
\text { load per } \\
\text { point }(\mathbf{k W})\end{array}$ & $\begin{array}{c}\text { number of } \\
\text { customers } \\
\text { per point }\end{array}$ \\
\hline LP1-LP4 & residential & 886.9 & 200 \\
\hline LP5 & residential & 813.7 & 200 \\
\hline LP6,LP7 & commercial & 671.4 & 10 \\
\hline
\end{tabular}

TABLE II

KEY PARAMETERS OF SIMULATION

\begin{tabular}{ll}
\multicolumn{1}{c}{ parameter } & \multicolumn{1}{c}{ value } \\
\hline EV battery size & $25 \mathrm{kWh}$ \\
\hline Peak charging power & $11 \mathrm{~kW}(3$ phase $)$ \\
\hline Energy consumption per km & $150 \mathrm{Wh} / \mathrm{km}$ \\
\hline Minimum SOC & $20 \%$ \\
\hline Maximum SOC & $85 \%$ \\
\hline Average driving distance & $40 \mathrm{~km}$ \\
\hline Line loading limit: L3 & $5600 \mathrm{~kW}$ \\
\hline
\end{tabular}

In order to study the long term incentives to the customers offered by the DT scheme, the cost savings of using the DT scheme are obtained through comparing the energy consumption costs under the DT scheme to those under the flat tariff scheme with a time frame of one year. The spot market prices of the studied year are shown in Fig. 1. The hourly conventional loads are obtained through scaling down the consumption data shown in Fig. 1 and matching the peak conventional load per load point specified in Table I. 
For the flat tariff scheme, the EVs are charged as soon as they arrive home according to the driving pattern study in [8] since the prices are flat and the owners will choose to charge the batteries at their earliest convenience. The energy costs are calculated for every day based on the spot prices and then summarized together to get the total cost for one year. Then the flat tariff (only the energy cost part is considered since the other parts are flat in the flat tariff scheme as well as in the DT scheme) is determined through dividing the total cost by the total energy consumption according to the principle stated in section II.A. Then the actual daily energy costs are obtained by multiplying the flat tariff with the daily energy consumption.

For the DT scheme, the method presented in [4] is employed. Firstly, the DSO determines the proper DT such that there is no congestion in the distribution network through optimal power flow. Then the aggregators make daily optimal energy plans for the EVs fulfilling the charging requirements based on the DT, including spot market prices. At the same time, the energy consumption costs are obtained.

The network conditions are examined in order to show the long term incentives to the DSO who offers the DT scheme to its customers.

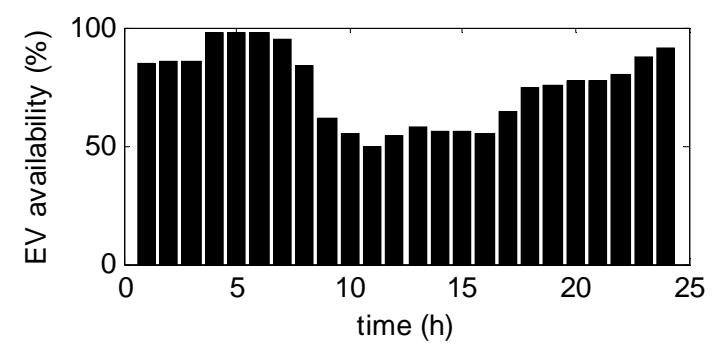

\section{RESUlTS AND DISCUSSIONS}

The simulations results are shown in Fig. 4 and Fig. 5. The daily cost of the first household at LP1 (before congestion point - L3) under the flat tariff scheme was plotted (Fig. 4). The cost for the first household at LP2 (after the congestion point) is the same (was not plotted) since they have the same consumption and tariff, which is 0.0318 [EUR/kWh] according to the calculation. The daily cost of the first household at LP1 and the cost of the first household at LP2 under the DT scheme were plot as well. The fluctuation of the cost curve under the DT scheme is because the fluctuation of the energy price. The total yearly cost of the first household at LP1 under the DT scheme is 625.96 [EUR] while the one for the first household at LP2 is 626.14 [EUR]. The cost difference between these two households is the congestion cost paid by the customers after the congestion point (L3), which is in this case so small that the two cost curves are not easy to be distinguished in Fig. 4. But both of them are less than the total cost for the first household under the flat tariff scheme, which is 651.67 [EUR], implying that the household using DT scheme can save cost of 25.53 25.71 [EUR] per year. This is the incentive why the household should choose the DT scheme.

From the DSO side, the incentive of employing the DT scheme is that the network operation conditions are improved which can be seen from Fig. 5, where L3 loading is always under the line loading limitation $(5600 \mathrm{~kW})$ under the DT scheme while overloading occurs several times under the flat tariff scheme. From the long term point of view, the cost savings from network investment can be achieved since the network operation conditions can be improved under the DT scheme and eventually the customers can benefit from this by paying less the tariff corresponding to the network investment and maintenance.

Fig. 3. EV availability

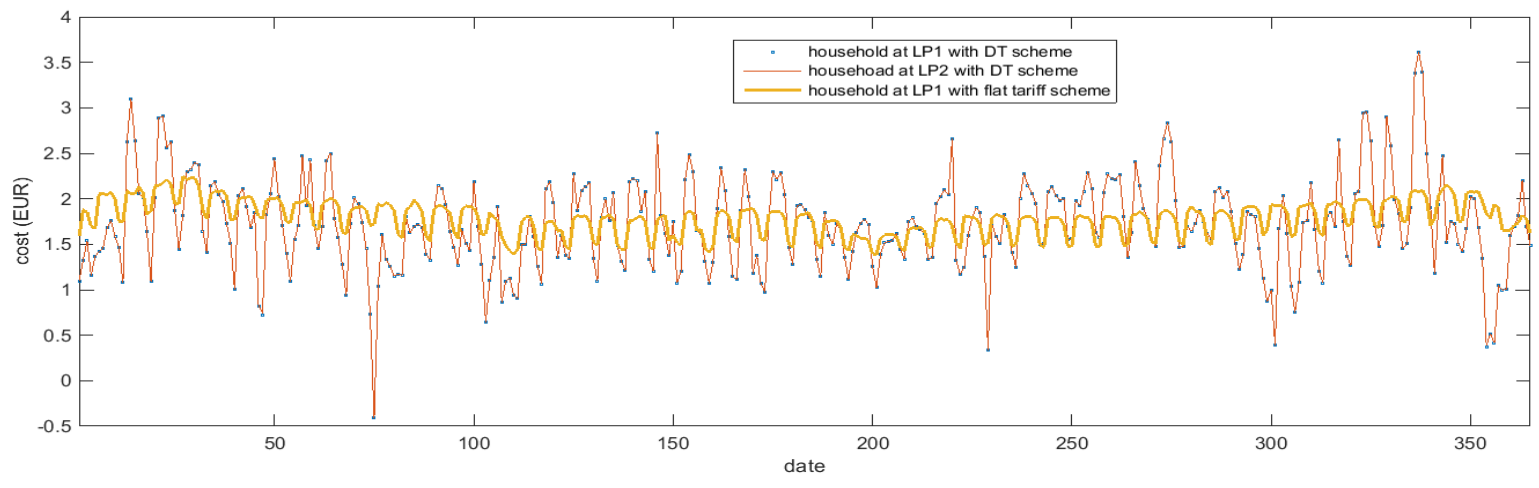

Fig. 4. Daily cost of the first household at LP1 and LP2 


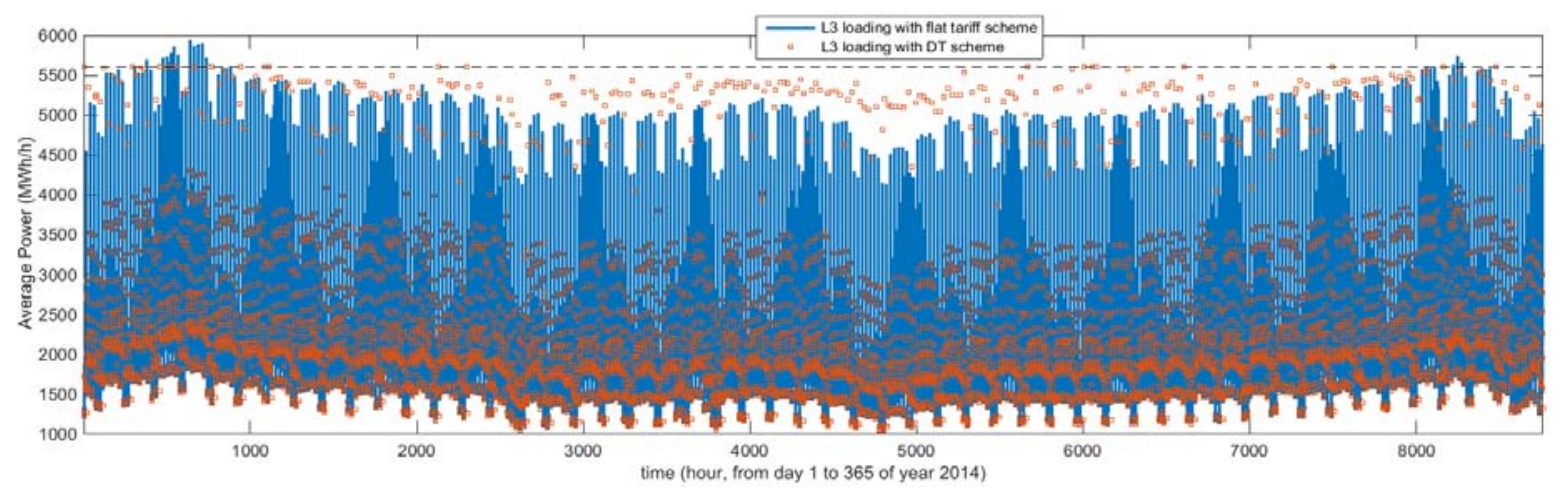

Fig. 5. L3 hourly loading comparison between two tariff schemes

\section{CONCLUSIONS}

This paper has investigated several tariff schemes, including the conventional flat tariff scheme and the newly introduced TOU, time-varying, DC and DT tariff schemes. It is shown that the DT scheme can offer the customers and the DSO long term incentives in terms of cost saving and network operation condition improving. Both time-varying and DT tariff schemes can benefit the power system by alleviating the system balance issue with the presence of large share of renewable energies, such as wind power, but only the DT scheme does not create new issues, such as congestion problem, for the distribution network.

In the future work, the DT scheme should be improved by removing the discrimination issue. Grid regulations should be studied as well and new suggestions can be made to allow the DT scheme to be employed.

\section{REFERENCES}

[1] (2015). Wind powers share of electricity consumption was 39 per cent in 2014. Energinet.dk, Denmark. [online]. Available: http://www.energinet.dk/EN/KLIMA-OGMILJOE/Miljoerapportering/VE-produktion/Sider/Vind.aspx.

[2] (2011, Feb. ). Energy strategy 2050. The Danish government, Copenhagen. [online]. Available: http://www.ens.dk/sites/ens.dk/files/dokumenter/publikationer/downloa ds/energy_strategy_2050.pdf.

[3] R. Li, Q. Wu, and S. S. Oren, “Distribution locational marginal pricing for optimal electric vehicle charging management," IEEE Trans. Power Syst., vol.29, no.1, pp. 203-211, Jan. 2014.

[4] S. Huang, Q. Wu, S. S. Oren, R. Li, and Z. Liu,"Distribution locational marginal pricing through quadratic programming for congestion management in distribution networks,” IEEE Trans. Power Syst., 2014, to be published.

[5] A. V. Stokke, G. L. Doorman, and T. Ericson, “An analysis of a demand charge electricity grid tariff in the residential sector," Energy Effic., vol.3, no.3, pp. 267-282, Jan. 2010.

[6] A. Ulbig and G. Andersson,"Towards variable end-consumer electricity tariffs reflecting marginal costs: A benchmark tariff,” in Proc. 2010 7th International Conference on the European Energy Market, pp. 1-6.

[7] R. N. Allan, R. Billinton, I. Sjarief, L. Goel, and K. S. So,“A reliability test system for educational purposes-basic distribution system data and results," IEEE Trans. Power Syst., vol.6, no.2, pp. 813-820, May 1991.

[8] Q. Wu, A. H. Nielsen, J. Østergaard, F. Marra, and C. Træholt,“Driving pattern analysis for electric vehicle (EV) grid integration study," in
Proc. 2010 IEEE PES Innovative Smart Grid Technologies Conference Europe (ISGT Europe), pp. 1-6. 